\title{
Current advance in bioconversion of methanol to chemicals
}

\author{
Wenming Zhang ${ }^{1,2}$, Meng Song ${ }^{1}$, Qiao Yang ${ }^{1}$, Zhongxue Dai ${ }^{1}$, Shangjie Zhang ${ }^{1}$, Fengxue Xin ${ }^{1,2}$, \\ Weiliang Dong ${ }^{1,2}$, Jiangfeng $\mathrm{Ma}^{1,2}$ and Min Jiang ${ }^{1,2^{*}}$
}

\begin{abstract}
Methanol has become an attractive substrate for biotechnological applications due to its abundance and low-price. Chemicals production from methanol could alleviate the environmental concerns, costs, and foreign dependency associated with the use of petroleum feedstock. Recently, a growing fraction of research has focused on metabolites production using methanol as sole carbon and energy source or as co-substrate with carbohydrates by native or synthetic methylotrophs. In this review, we summarized the recent significant progress in native and synthetic methylotrophs and their application for methanol bioconversion into various products. Moreover, strategies for improvement of methanol metabolism and new perspectives on the generation of desired products from methanol were also discussed, which will benefit for the development of a methanol-based economy.
\end{abstract}

Keywords: Methanol, Methylotrophs, Industrial biotechnology, Bio-based chemicals

\section{Background}

Biotechnological production of fuels and chemicals has been considered as an alternative to petroleum-derived products [1]. In general, the cost of raw material accounts for most of total cost in biotechnological processes [2]. In white biotechnology, many low-cost raw materials, such as bagasse, sugar cane molasses and corn starch hydrolysates are widely used; however, the usage of carbohydrates derived from crops will competes with human demanding [3]. At present, lignocellulose has been proposed as a promising raw material for biosynthesis of fuels and chemicals, while several problems still exist, such as inefficient biocatalysts and high processing costs [3]. Thus, the adoption of low-price carbon substrates is still needed in the commercialization of industrial biotechnology [4].

Methanol, a non-food feedstock, has been considered as a next-generation carbon source due to its abundance and low-price [5]. Compared to other low-cost

\footnotetext{
*Correspondence: bioengine@njtech.edu.cn

1 State Key Laboratory of Materials-Oriented Chemical Engineering,

College of Biotechnology and Pharmaceutical Engineering, Nanjing Tech University, No. 30 Puzhu Road, Pukou District Nanjing, Nanjing 211816,

People's Republic of China

Full list of author information is available at the end of the article
}

plant-derived feedstocks like molasses, methanol is purer and can be completely consumed in microbial metabolism. Degree of reduction per carbon of methanol is 6 while that of glucose is 4 . Thus, more electrons are available, which can enhance the yield of biofuels and chemicals [6]. Furthermore, the use of methanol reduces the risk of contaminations, and residual methanol can easily be removed by elevated temperature [7]. Importantly, methanol price continues to slide due to the maturity of the methanol production process [8]. Therefore, biosynthesis of chemicals from methanol has attracted much interest, representing a promising process [9].

Methylotrophs, which can utilize reduced C1 compounds as sole carbon source for growth, have been used for the production of various valuable chemicals (Fig. 1). In nature, methylotrophs can be divided into two groups, methylotrophic bacteria and yeasts. To overcome inefficient genetic-transfer systems and low yields of desirable metabolites, synthetic methylotrophy has become an increasing attention. Within this review, we summarized the current significant progress using native and synthetic methylotrophy and their use for methanol bioconversion into various products (Table 1 ). In addition, some strategies for improvement of methanol metabolism 


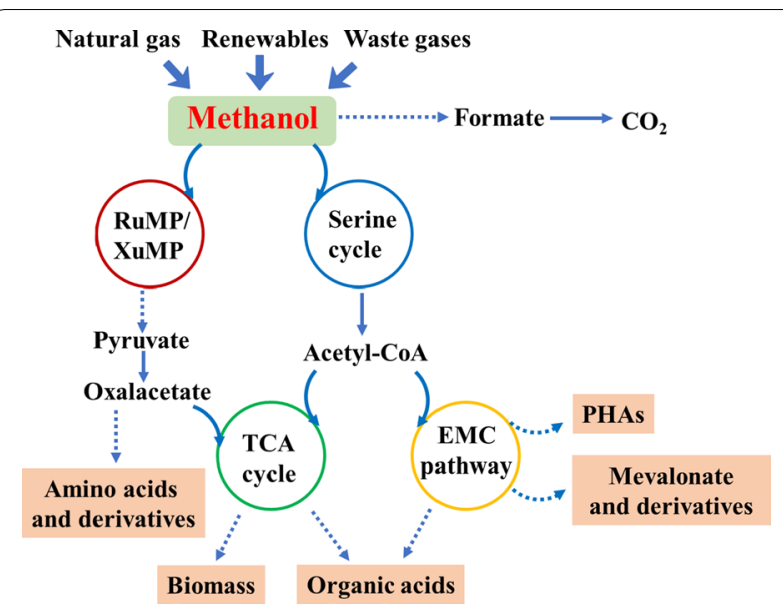

Fig. 1 Schematics of various of chemicals production from methanol. Methanol obtained from different resources can be oxidized to $\mathrm{CO}_{2}$ by dissimilation or enter the carbon metabolic pathways and converted into chemicals via certain assimilation pathways. Solid arrows represent one step reactions, while dotted arrows show multi-step reactions

and production of more value-added products were discussed.

\section{Polyhydroxyalkanoates}

Microbial synthesis of polyhydroxyalkanoates (PHAs) as a potential sustainable replacement for non-degradable petroleum-based plastics has attracted wide attention due to their biocompatibility and biodegradability [10, 11]. PHAs are naturally produced by bacteria and archaea from various carbon sources, such as saccharides, $n$-alkanes, $n$-alcohols and gases [12]. Based on the advantages of methanol as substrate, the application of methylotrophs is regarded as a promising way for biosynthesis of PHAs from methanol [13]. Recently, many efforts have been made to enhance the PHAs content and control the PHA structures to form homopolymers, random copolymers and block copolymers for diversity of material properties [14]. Methylobacterium extorquens was able to use methanol as sole carbon and energy source for the production of poly-3-hydroxybutyrate (PHB). M. extorquens AM1 has been studied for PHB production more than 30 years, and produced the PHB titer to $149 \mathrm{~g} / \mathrm{L}$ [15] $M$. extorquens ATCC 55366 accumulated PHB up to $46 \%$, while PHB yield was only $0.09 \mathrm{~g} / \mathrm{g}$ methanol. Moreover, higher molecular weight PHB (900-1800 kDa) will be produced under methanol-limiting conditions $(<0.01 \mathrm{~g} / \mathrm{L})$ [16]. Media components optimization was an effective strategy for cell growth and PHB production. When $0.12 \mathrm{~g} / \mathrm{L}$ of $\mathrm{NH}_{4}{ }^{+}$was added, Methyloligella halotolerans $\mathrm{C} 2$ could produce $7.04 \mathrm{~g} / \mathrm{L}$ of $8000-10,000 \mathrm{kDa}$ PHB [17]. Under a deficiency of nitrogen and magnesium condition, $62.3 \%$ of DCW and $9.5 \mathrm{~g} / \mathrm{L}$ of PHB with yield of $0.16 \mathrm{~g} / \mathrm{g}$ were generated by $M$. extorquens DSMZ 1340 [18].

Due to the limited rigidity and brittleness of the PHB structure, further studies were focused on functionalized PHAs containing $\mathrm{C}-\mathrm{C}$ double bonds produced when unsaturated carboxylic acids were used as an auxiliary carbon source $[19,20]$. The co-polyester poly3-hydroxybutyrate-poly-3-hydroxyvalerate (PHB/HV) was accumulated in Methylobacterium sp. strain GW2, using valeric acid as co-substrates. Moreover, an average molecular mass of biopolymers was $229-233 \mathrm{kDa}$ for PHB and 362-411 kDa for PHB/HV [21]. M. extorquens AM1 was able to synthesize $\mathrm{P}(3 \mathrm{HB}-c o-3 \mathrm{HV})$ copolymers from methanol as a sole carbon source under cobalt-limited conditions. After genetic engineered, a recombinant strain could produce a PHA terpolymer composed of $3 \mathrm{HB}, 3 \mathrm{HV}$, and a C6-monomer, $(R)$-3-hydroxyhexanoate, indicating it was possible to produce practical PHA copolymers by methylotrophic bacteria using methanol as a feedstock [13]. Due to the cheaper cost of methanol compared to pure sugar substrates, the use of methylotrophs for the production of PHA could reduce PHA cost. However, the content of PHA from methanol (46\% cell dry mass) is lower than that from sugars (50-88\% cell dry mass) [19]. Moreover, methanol concentration was no more than $100 \mathrm{mM}$ during fermentation, and the tolerance of strain to methanol should be improved for the industrial application. Moreover, further study is needed to improve the content and yield of PHA before industrialized production.

\section{Amino acids}

Amino acids are widely used as food and feed additives, flavor enhancers, pharmaceuticals and polymer materials [22, 23]. At present, microbial fermentation is still the primary way for large scaling amino acid production, in which the main producer is Corynebacterium glutamicum [24]. To reduce production cost, many cheap substrates, such as molasses and starch were developed for the production of amino acids. In parallel, some microorganisms utilizing more inexpensive and non-food substrates were explored to reduce production cost [23].

Many native and engineered methylotrophs were used to overproduce different amino acids including glutamate, lysine, serine, and threonine from methanol [2532]. For example, Methylobacillus glycogenes RV3 can produce $38.8 \mathrm{~g} / \mathrm{L}$ of L-glutamate. After chemical mutagenized with $N$-methyl- $N^{\prime}$-nitro- $N$-nitrosoguanidine (NTG), a mutant AL119 can secret $11 \mathrm{~g} / \mathrm{L}$ of L-threonine, and mutant DHL 122 can produce $3.1 \mathrm{~g} / \mathrm{L}$ of L-lysine and $5.6 \mathrm{~g} / \mathrm{L}$ of L-threonine [25]. When overexpressed a dihydrodipicolinate synthase from M. glycogenes, $37 \mathrm{~g} / \mathrm{L}$ 
Table 1 Various of chemicals production using native or synthetic methylotrophs

\begin{tabular}{|c|c|c|c|c|c|}
\hline Substance class & Product & Concentration & Yield & Organism & Reference \\
\hline \multirow[t]{6}{*}{$\mathrm{PHAs}$} & PHB & $40-52.9 \mathrm{~g} / \mathrm{L}$ & $0.09-0.12 \mathrm{~g} / \mathrm{g}$ & M. extorquens ATCC 55366 & {$[16]$} \\
\hline & & $9.5 \mathrm{~g} / \mathrm{L}$ & $0.16 \mathrm{~g} / \mathrm{g}$ & M. extorquens DSMZ 1340 & [18] \\
\hline & & $136 \mathrm{~g} / \mathrm{L}$ & $0.18 \mathrm{~g} / \mathrm{g}$ & Pseudomonas sp. K & {$[90]$} \\
\hline & PHB (8000 -10,000 kDa) & $7.04 \mathrm{~g} / \mathrm{L}$ & $0.17 \mathrm{~g} / \mathrm{g}$ & M. halotolerans C2 & {$[17]$} \\
\hline & $\mathrm{PHB}-\mathrm{CO}-\mathrm{HV}$ & $\sim 1 \mathrm{~g} / \mathrm{L}$ & $0.17 \mathrm{~g} / \mathrm{g}$ & Methylobacterium sp. strain GW2 & {$[21]$} \\
\hline & $\mathrm{PHB}-\mathrm{CO}-\mathrm{HV}$ & $2.34 \mathrm{~g} / \mathrm{L}$ & - & Methylocystis sp. WRRC1 & {$[91]$} \\
\hline \multirow[t]{8}{*}{ Amino acids } & L-Glutamate & $38.8 \mathrm{~g} / \mathrm{L}$ & $\sim 0.13 \mathrm{~g} / \mathrm{g}$ & M. glycogenes & {$[25]$} \\
\hline & & $55 \mathrm{~g} / \mathrm{L}$ & $0.36 \mathrm{~g} / \mathrm{g}$ & Bacillus methanolicus MGA3 & {$[27,28]$} \\
\hline & L-Threonine & $11 \mathrm{~g} / \mathrm{L}$ & - & M. glycogenes AL119 & {$[25]$} \\
\hline & L-Lysine & $8 \mathrm{~g} / \mathrm{L}$ & - & $\begin{array}{l}\text { Introduction of the dapA gene } \\
\text { encoding dihydrodipicolinate } \\
\text { synthase into M. glycogenes } \\
\text { AL119 }\end{array}$ & {$[26]$} \\
\hline & & $35 \mathrm{~g} / \mathrm{L}$ & - & $\begin{array}{l}\text { B. methanolicus MGA3 mutant } \\
\text { 13A52-8A66 }\end{array}$ & {$[27]$} \\
\hline & & $11.3 \mathrm{~g} / \mathrm{L}$ & - & $\begin{array}{l}\text { Expressed L-lysine/L-arginine } \\
\text { exporter (LysE) in M. methylo- } \\
\text { trophus }\end{array}$ & {$[30]$} \\
\hline & L-Serine & $54.5 \mathrm{~g} / \mathrm{L}$ & $\begin{array}{l}\text { 8.3\% from methanol, } 39.3 \% \text { from } \\
\text { glycine }\end{array}$ & M. extorquens & {$[31]$} \\
\hline & & $65 \mathrm{mg} / \mathrm{mL}$ & $0.62 \mathrm{~g} / \mathrm{g}$ & Methylobacterium sp. MN43 & {$[32]$} \\
\hline \multirow[t]{3}{*}{ Organic acids } & Pyruvate & $0.26 \mathrm{~g} / \mathrm{L}$ & $0.25 \mathrm{~g} / \mathrm{g}$ & $\begin{array}{l}\text { The methanol metabolic path- } \\
\text { ways originating from P. pasto- } \\
\text { ris were constructed into the } \\
\text { chromosome of S. cerevisiae }\end{array}$ & {$[2]$} \\
\hline & Mesaconic & $70 \mathrm{mg} / \mathrm{L}$ & $0.0175 \mathrm{~g} / \mathrm{g}$ & $\begin{array}{l}\text { Expressed thioesterase yciA in } M \text {. } \\
\text { extorquens }\end{array}$ & {$[44]$} \\
\hline & Methylsuccinic acid & $60 \mathrm{mg} / \mathrm{L}$ & $0.015 \mathrm{~g} / \mathrm{g}$ & $\begin{array}{l}\text { Expressed thioesterase yciA in } M \text {. } \\
\text { extorquens }\end{array}$ & {$[44]$} \\
\hline \multirow[t]{5}{*}{ Fine chemicals } & Mevalonate & $2.67 \mathrm{~g} / \mathrm{L}$ & $0.085 \mathrm{~g} / \mathrm{g}$ & $\begin{array}{l}\text { Biosensor-assisted transcrip- } \\
\text { tional regulator engineering } \\
\text { used for M. extorquens }\end{array}$ & {$[54]$} \\
\hline & a-Humulene & $1.65 \mathrm{~g} / \mathrm{L}$ & $0.031 \mathrm{~g} / \mathrm{g}$ & $\begin{array}{l}\text { Expressed a-humulene synthase } \\
\text { and farnesyl pyrophosphate } \\
\text { synthase in M. extorquens }\end{array}$ & {$[56]$} \\
\hline & Naringenin & $3.5 \mathrm{mg} / \mathrm{L}$ & $4.7 \%{ }^{13} \mathrm{C}$-labeling in naringenin & $\begin{array}{l}\text { The pathways for methanol } \\
\text { assimilation and naringenin } \\
\text { synthesis were introduced into } \\
\text { E. coli }\end{array}$ & {$[60]$} \\
\hline & Monacolin J & $593.9 \mathrm{mg} / \mathrm{L}$ & $0.35 \mathrm{mg} / \mathrm{g}$ & $\begin{array}{l}\text { The biosynthetic pathways for } \\
\text { monacolin J and lovastatin } \\
\text { were assembled into P. pastoris }\end{array}$ & {$[65]$} \\
\hline & Lovastatin & $250.8 \mathrm{mg} / \mathrm{L}$ & $0.15 \mathrm{mg} / \mathrm{g}$ & $\begin{array}{l}\text { The biosynthetic pathways for } \\
\text { monacolin J and lovastatin } \\
\text { were assembled into P.pastoris }\end{array}$ & {$[65]$} \\
\hline \multirow[t]{3}{*}{ Other chemicals } & Cadaverine & $11.3 \mathrm{~g} / \mathrm{L}$ & - & $\begin{array}{l}\text { Expressed lysine decarboxylase } \\
\text { in B. methanolicus }\end{array}$ & {$[67]$} \\
\hline & & $1.5 \mathrm{~g} / \mathrm{L}$ & - & $\begin{array}{l}\text { The pathways for methanol } \\
\text { assimilation and lysine decar- } \\
\text { boxylase were introduced into } \\
\text { C. glutamicum }\end{array}$ & {$[64]$} \\
\hline & Y-Aminobutyric acid & $9 \mathrm{~g} / \mathrm{L}$ & - & $\begin{array}{l}\text { Expressed glutamate decarboxy- } \\
\text { lase in B. methanolicus MGA3 }\end{array}$ & {$[77]$} \\
\hline
\end{tabular}


Table 1 (continued)

\begin{tabular}{|c|c|c|c|c|c|}
\hline Substance class & Product & Concentration & Yield & Organism & Reference \\
\hline \multirow[t]{3}{*}{ Proteins } & Green fluorescent protein (GFP) & $4 \mathrm{~g} / \mathrm{L}$ & $0.3 \mathrm{~g} / \mathrm{g}$ & $\begin{array}{l}\text { Expressed green fluorescent } \\
\text { protein in M. extorquens }\end{array}$ & [82] \\
\hline & Enterocin P & $155 \mathrm{ng} / \mathrm{mL}$ & - & $\begin{array}{l}\text { Expressed the Enterocin P struc- } \\
\text { tural gene in } M \text {. extorquens }\end{array}$ & [84] \\
\hline & Cry1Aa & $1.26 \mathrm{mg} / \mathrm{L}$ & $\begin{array}{l}9 \mathrm{mg} / \mathrm{g} \mathrm{DCW}, 4.5 \% \text { of total } \\
\text { protein }\end{array}$ & Engineered $M$. extorquens & [85] \\
\hline
\end{tabular}

of glutamate and $8 \mathrm{~g} / \mathrm{L}$ of lysine were accumulated in $M$. glycogenes DHL122 at $37{ }^{\circ} \mathrm{C}$ [26]. The methylotrophic bacterium Bacillus methanolicus is a promising candidate for amino acid production from methanol. Because genes involved in methanol metabolism are plasmidencoded, which can be upregulated in cells utilizing methanol, B. methanolicus MGA3 has high methanol consumption rate. It can produce $59 \mathrm{~g} / \mathrm{L}$ of L-glutamate and $0.4 \mathrm{~g} / \mathrm{L}$ of L-lysine at $50{ }^{\circ} \mathrm{C}$ in fed-batch cultivation, using methanol as carbon source $[27,28]$. Due to the lack of efficient genetic tools, random chemical mutagenesis was the main method for strains engineering [24, 29]. For example, $11 \mathrm{~g} / \mathrm{L}$ of L-lysine and $69 \mathrm{~g} / \mathrm{L}$ of L-glutamate were accumulated in an $S$-(2-aminoethyl)-cysteine-resistant mutant M168-20 [28]. A homoserine dehydrogenase mutant, 13A52-8A66 was found to secret $35 \mathrm{~g} / \mathrm{L}$ of L-lysine and $28 \mathrm{~g} / \mathrm{L}$ of L-glutamate [27].

An excretion transport system is crucial to amino acids production. When the $\mathrm{L}$-lysine/L-arginine exporter (LysE) from C. glutamicum was expressed in Methylophilus methylotrophus, the production of L-lysine was improved to $11.3 \mathrm{~g} / \mathrm{L}$, suggesting that amino acid exportation systems would facilitate amino acid production [30]. Due to the serine cycle, $M$. extorquens can produce serine from methanol and glycine. In resting cells of M. extorquens, $54.5 \mathrm{~g} / \mathrm{L}$ of L-serine was achieved under appropriate conditions. The yield can be up to $8.3 \%$ from methanol and $39.3 \%$ from glycine, respectively [31]. Similarly, $65 \mathrm{mg} / \mathrm{mL}$ of L-serine were obtained from $104 \mathrm{mg} /$ $\mathrm{mL}$ of methanol and $50 \mathrm{mg} / \mathrm{mL}$ of glycine in resting cells of Methylobacterium sp. MN43 when L-serine degradation was blocked [32].

Substrate consumption rate and product yield are important indicators for microbial production processes. It was reported that cell growth rate and methanol consumption rate can up to $0.4 / \mathrm{h}$ and $7 \mathrm{~g} /(\mathrm{L} \mathrm{h})$ in $B$. methanolicus MGA3, which is close to cell growth rate $(0.53 / \mathrm{h})$ and glucose consumption rate $[6.6 \mathrm{~g} /(\mathrm{L} \mathrm{h})]$ in $C$. glutamicum [7, 33]. Moreover, the theory yield of L-lysine from methanol $(0.71 \mathrm{~g} / \mathrm{g})$ by B. methanolicus is the same as that from glucose $(0.78 \mathrm{~g} / \mathrm{g})$ by C. glutamicum [23]. Importantly, $B$. methanolicus are able to grow at temperatures from 35 to $60{ }^{\circ} \mathrm{C}$ with a growth optimum around
$50-55{ }^{\circ} \mathrm{C}$ [34]. Based on the above advantages, biosynthesis of amino acids from methanol by $B$. methanolicus represents a promising and sustainable method.

\section{Organic acids}

Organic acids, especially for low molecular weight carboxylic acids, have been widely applied in food, pharmaceutical, cosmetic, detergent, polymer, and textile industry [35]. In view of the crisis of fossil fuels and concerns of environmental pollution, more attention has been given to the production of organic acids via fermentation using renewable feedstocks. In the last decade, several organic acids were produced via biorefinery using various types of microorganisms, such as succinic acid production by E. coli $[36,37]$ or Yarrowia lipolytica [38, 39], malic acid production by Aspergillus oryzae [40, 41], citric acid production by Aspergillus niger [42] and itaconic acid production by Aspergillus terreus [43]. To realize industrial production and make the bioprocess more economical, adoption of inexpensive feedstock for organic acids production offers a promising alternative. Based on advantages of abundant sources, low-cost, highly reduced and non-food substance, methanol has gained more attractive attention for biotechnological processes.

Saccharomyces cerevisiae was metabolic engineered to achieve pyruvate production from methanol by expressing the methanol metabolic module originated from Pichia pastoris [2]. The results showed that $0.26 \mathrm{~g} / \mathrm{L}$ of pyruvate with a yield of $0.25 \mathrm{~g} / \mathrm{g}$ was achieved from methanol. The biomass was increased 3.13\% compared to the wild-type strain. Moreover, the consumption of methanol was improved when $1 \mathrm{~g} / \mathrm{L}$ of yeast extract was supplemented. Given that, some dicarboxylic acids, such as malic acid and succinic acid, could be also produced from methanol if the enzymes of reductive tricarboxylic acid (rTCA) pathway were introduced into this strain. However, methanol utilization rate and metabolites production should be improved by the application of available genetic tools, such as harboring inducible promoters and balancing the cooperation of enzymes. It's worth noting that methanol is first oxidized to formaldehyde by methanol dehydrogenase, while formaldehyde dissimilation 
into $\mathrm{CO}_{2}$ is ubiquitous in organisms. Therefore, to enhance the metabolic flux from methanol to metabolites, formaldehyde dissimilation should be blocked. Furthermore, the regeneration of xylulose 5-phosphate is crucial to sustain the pathway running (Fig. 2).

Some uncommon dicarboxylic acids, such as ethylmalonic acid, methylsuccinic acid, mesaconic acid and methylmalic acid, can also be produced from methanol [44]. The ethylmalonyl-CoA pathway (EMCP), harboring several saturated or unsaturated carboxylated C4- and C5-acyl-CoA esters, was discovered in the methylotroph M. extorquens AM1 $[45,46]$. YciA, an acyl-CoA thioester hydrolase, was heterologously expressed in $M$. extorquens AM1, leading to production of $70 \mathrm{mg} / \mathrm{L}$ mesaconic and $60 \mathrm{mg} / \mathrm{L}$ methylsuccinic acid from methanol [44]. This work provides the possibility of EMCP-derived dicarboxylic acids production by other thioesterases.

\section{Fine chemicals}

Terpenoids and sesquiterpenoids are widely used for drugs, flavors and fragrances, representing a large class of natural products, such as sterols and carotenoids [47-49]. In nature, they are produced by the mevalonate

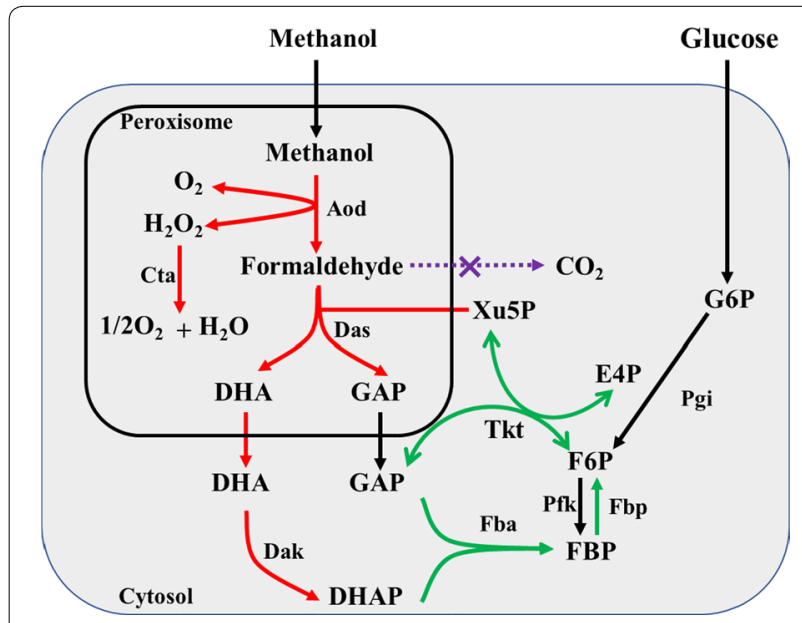

Fig. 2 Strategies to enhance the metabolic flux from methanol to metabolites. Methanol is first oxidized to formaldehyde by peroxisomal enzyme alcohol oxidase, which is assimilated via the xylulose 5-phosphate pathway (XuMP) (red lines). Formaldehyde dissimilation pathway is blocked (purple line). The regeneration of xylulose 5-phosphate is improved by overexpressed genes of pentose phosphate pathway (green lines). Enzymes: Aod, alcohol oxidase; Cta, catalase; Das, dihydroxyacetone synthase; Dak, dihydroxyacetone kinase; Tkt, transketolase; Fba, fructose-bisphosphate aldolase; Pfk, phosphofructokinase; Fbp, fructose bisphosphatase; Pgi, phosphoglucose isomerase. Metabolites, DHA, dihydroxyacetone; DHAP, dihydroxyacetone phosphate; GAP, glyceraldehyde 3-phosphate; F6P, fructose 6-phosphate; FBP, fructose

1,6-bisphosphate; Xu5P, xylulose 5-phosphate; E4P, erythrose 4-phosphate; G6P, glucose 6-phosphate
(MVA) pathway or methylerythritol 4-phosphate (MEP) pathway [50]. In the MVA pathway, two molecules of acetyl-CoA were converted into acetoacetyl-CoA by acetoacetyl-CoA synthase, which is naturally present in $M$. extorquens. This feature suggests that $M$. extorquens is a promising candidate for terpenoid and derivative biosynthesis, because it is difficult to heterologous express an active acetoacetyl-CoA synthase in chassis organism [51]. In addition, since no native MVA pathway exists, a heterologous MVA pathway will not be interfered by endogenous regulation [52].

To achieve mevalonate production, a natural operon and an artificial operon employing key enzymes of the MVA pathway were introduced into $M$. extorquens AM1, resulting in 56 and $66 \mathrm{mg} / \mathrm{L}$ of mevalonate obtained in shake flask fermentations, respectively. Increasing flux of the precursor acetyl-CoA towards acetoacetyl-CoA by expressing phaA gene (encoding acetoacetyl-CoA thiolase) from Ralstonia eutropha achieved $80 \mathrm{mg} / \mathrm{L}$ of mevalonate. Further regulation of phaA expression using different strengths RBSs (ribosomal binding sites) produced $215 \mathrm{mg} / \mathrm{L}$ of mevalonate. Finally, $2.22 \mathrm{~g} / \mathrm{L}$ of mevalonate with a yield and productivity of $28.4 \mathrm{mg} / \mathrm{g}$ and $7.16 \mathrm{mg} /(\mathrm{L} \mathrm{h})$ was obtained in fed-batch fermentation, representing the first reported de novo synthesized mevalonate from methanol [49]. To further decrease the cost and improve the titer, the medium was optimized by changing the concentration of phosphate and trace elements. The mevalonate production reached $340 \mathrm{mg} / \mathrm{L}$ using the optimized medium. In $5 \mathrm{~L}$ fed-batch fermentation, mevalonate concentration, yield and productivity reached $2.59 \mathrm{~g} / \mathrm{L}, 48.90 \mathrm{mg} / \mathrm{g}$ and $12.33 \mathrm{mg} /(\mathrm{L} \mathrm{h})$, respectively [53]. It is known that acetyl-CoA is a key precursor for the synthesis of mevalonate. To increase carbon metabolic flux into acetyl-CoA for mevalonate synthesis, a biosensor-assisted transcriptional regulator QscR was used to control metabolic flux re-distribution. The results of ${ }^{13} \mathrm{C}$-labeling suggested that acetyl-CoA flux was improved by $7 \%$. Further transcriptional analysis revealed that NADPH generation and fumC (encoding fumarase C) overexpression were two main factors for the metabolic flux re-distribution. Finally, $2.67 \mathrm{~g} / \mathrm{L}$ of mevalonate with yield of $0.085 \mathrm{~g} / \mathrm{g}$ was obtained by fed-batch fermentation, representing the highest yield in engineered $M$. extorquens AM1 [54]. This strategy provides not only a method for the effective synthesis of mevalonate, terpenoids and other derivatives, but also a new way for the refinery and improvement of the production of other products based on acetyl-CoA, such as fatty acids and derivatives.

$\alpha$-Humulene, a monocyclic sesquiterpenoid, has raised wide attention due to its anti-inflammatory and potential anti-cancer properties [55]. For production of 
$\alpha$-humulene, $\alpha$-humulene synthase and farnesyl pyrophosphate (FPP) synthase were heterologously expressed in M. extorquens AM1 [56]. The engineered strain produced $18 \mathrm{mg} / \mathrm{L}$ of $\alpha$-humulene, representing the first synthesis of $\alpha$-humulene from methanol. When a prokaryotic MVA pathway from Myxococcus xanthus together with RBS optimized $\alpha$-humulene synthase and FPP synthase were introduced into AM1, the engineered strain produced $58 \mathrm{mg} / \mathrm{L}$ of $\alpha$-humulene. To further reduce the flux of by-product carotenoid from FPP, a diapolycopenedial formation deficient strain was used [57], resulting in $1.65 \mathrm{~g} / \mathrm{L}$ of $\alpha$-humulene with yield of $0.031 \mathrm{~g} / \mathrm{g}$ produced in fed-batch fermentation, representing the highest concentration for de novo synthesis of $\alpha$-humulene to date.

Besides native methylotrophs, the concept of synthetic methylotrophy has attracted much interest. Recently, efforts towards achieving methanol utilization were reported in E. coli [58-62] and Corynebacterium glutamicum $[63,64]$. And more and more chemicals have been synthesized from methanol in these platform microorganisms [60-64]. The flavanone naringenin is the first example of methanol bioconversion in methylotrophic $E$. coli [60]. Whitaker et al. expressed methanol dehydrogenase (Mdh) from B. stearothermophilus in combination with ribulose monophosphate (RuMP) pathway enzymes from B. methanolicus for methanol utilization in E. coli. ${ }^{13} \mathrm{C}$-labeling showed that the intermediate in glycolytic, TCA cycle and some amino acids can be labeled; demonstrating methanol was assimilated by the recombinant E. coli. To demonstrate that methanol was able to be converted to chemicals, the naringenin biosynthesis pathway was incorporated into methylotrophic E. coli strain. The results revealed up to $4.7 \%{ }^{13} \mathrm{C}$-labeling in naringenin and $18 \%$ of the total naringenin pool contained at least one carbon labeled. Importantly, they firstly found the methanol assimilation can be improved during growth with small amounts of yeast extract. To further elucidate the mechanism, ${ }^{13} \mathrm{C}$-tracers experiments were used to examine intracellular metabolites during methanol assimilation [61]. Twenty five potential co-substrates were evaluated, indicating threonine was the optimum co-substrate for methanol assimilation. Then the threonine degradation pathway was improved by deletion of the repressor Lrp, which led to the improvement of biomass [61].

Recently, it was reported that a methylotrophic yeast was used to produce pharmaceuticals from methanol. The biosynthesis module of monacolin J and lovastatin were assembled in Pichia pastoris using methanol as the sole carbon source, leading to $60.0 \mathrm{mg} / \mathrm{L}$ of monacolin J and $14.4 \mathrm{mg} / \mathrm{L}$ of lovastatin production in $\mathrm{pH}$-controlled monoculture [65]. To relieve imbalance metabolism and metabolic stress in monoculture, the pathways were split and re-distributed in a $P$. pastoris- $P$. pastoris consortium. The results proved that production of monacolin $J$ and lovastatin were improved by $55 \%$ and $71 \%$. Finally, $593.9 \mathrm{mg} / \mathrm{L}$ of monacolin J and $250.8 \mathrm{mg} / \mathrm{L}$ of lovastatin were obtained in bioreactor fermentations. This work not only provides the feasibility of a methylotrophic yeast for production of pharmaceuticals, but also offers a new view to produce chemicals from methanol using coculture system. Microbial co-cultures have the ability to reduce metabolic burden, enhance systematic robustness and improve target chemicals production [66]. For example, one strain used to convert methanol to intermediate metabolites, followed by its conversion to other products by the other strain. Importantly, the functions of microbial consortia should be optimized, including optimization of metabolite exchange and control of molecular signaling pathways, electron transfer, and cofactor.

\section{Other chemicals}

Besides the aforementioned chemicals, some valueadded chemicals can also obtain from methanol by native and synthetic methylotrophs, such as cadaverine and $\gamma$-aminobutyric acid. The diamine 1,5-diaminopentane (cadaverine), a monomeric polyamide building block, is an important platform chemical used for production of various polyamides and mainly manufactured by petroleum-based raw materials [67]. Facing the threat of oil depletion and environmental pollution, many efforts have been made for improving the production process of polyamines from renewable resources [68]. Cadaverine has been generated from various raw materials, such as starch or hemicellulose through biological fermentation $[69,70]$. Recently, methanol-based cadaverine can also be produced by methylotrophic or non-methylotrophic organisms. Although cadaverine is a non-native product, it can be obtained from lysine decarboxylation by lysine decarboxylase. The facultative methylotrophic bacterium B. methanolicus is a great candidate for L-lysine overproduction, because the maximum theoretical yield can reach $0.82 \mathrm{~g} / \mathrm{g}$ from methanol, which is comparable to the maximum yield from glucose in C. glutamicum [23, 71]. Two different lysine decarboxylase genes $c a d A$ and $l d c C$ from E. coli were introduced into B. methanolicus. Results showed that strains expressing cadA produced $0.5 \mathrm{~g} / \mathrm{L}$ of cadaverine in shake flask conditions. Finally, the production of cadaverine can reach up to $11.3 \mathrm{~g} / \mathrm{L}$ from methanol in high density fermentation [67]. C. glutamicum can produce $120 \mathrm{~g} / \mathrm{L}$ lysine in fed-batch fermentation [72], representing a promising candidate for cadaverine production. After heterologous expressed cadA encoding lysine decarboxylase from $E$. coli, the engineered C. glutamicum produced $2.3 \mathrm{~g} / \mathrm{L}$ of cadaverine with yield of $0.17 \mathrm{~g} / \mathrm{g}$ [73]. Synthetic methylotrophic 
C. glutamicum was also able to produce cadaverine using methanol as co-substrate [64]. Methanol dehydrogenase and RuMP pathway enzymes from B. methanolicus and lysine decarboxylase LdcC from $E$. coli were employed for methanol utilization and cadaverine synthesis in C. glutamicum, respectively. $1.5 \mathrm{~g} / \mathrm{L}$ of cadaverine was obtained in shake flask fermentation when methanol was used as an auxiliary substrate [64]. ${ }^{13} \mathrm{C}$-labeling experiments revealed that labeling of cadaverine was detected; indicating ${ }^{13} \mathrm{C}$-methanol was indeed converted to cadaverine by methanol assimilation. However, compared with methylotrophic bacterium B. methanolicus, synthetic methylotrophic C. glutamicum cannot sustain growth on methanol alone in a defined medium. Moreover, only about $5 \%$ labeled carbon was observed when used minimal medium containing $50 \mathrm{mM}$ glucose and $50 \mathrm{mM}$ ${ }^{13} \mathrm{C}$-methanol [64]. Therefore, further studies are still needed to increase titer and yield by synthetic biology or process design.

$\gamma$-Aminobutyric acid (GABA), a non-protein amino acid, has been widely studied due to its numerous physiological and pharmacological functions. The biosynthesis of GABA is the decarboxylation of L-glutamate by glutamate decarboxylase (GAD), which has been found in bacteria, plants and insects [74]. In recent years, several GABA-producing strains were isolated or engineered for the efficient production of GABA $[75,76]$. Methanol-based GABA production was also achieved by engineering methylotrophic B. methanolicus [77]. Two glutamate decarboxylase genes gadSt (from Sulfobacillus thermosulfidooxidans) and $\operatorname{gadB}$ (from $E$. coli) were heterologously expressed in B. methanolicus, respectively. From the shake flask experiments, the strain expressing $\operatorname{gadB}$ produced higher GABA $(0.4 \mathrm{~g} / \mathrm{L})$ than that of the strain expressing gadSt $(0.03 \mathrm{~g} / \mathrm{L})$. However, $29 \mathrm{~g} / \mathrm{L}$ of L-glutamate and $0.1 \mathrm{~g} / \mathrm{L}$ of GABA were accumulated in methanol fed-batch fermentation, indicating glutamate decarboxylase was inactive. After two-phase fermentation strategy and the $\mathrm{pH}$ shift were employed, the final production of GABA was increased to $9 \mathrm{~g} / \mathrm{L}$, which provides a new process of production of GABA and its derivates, such as biodegradable plastic polyamide 4 .

\section{Proteins}

After World War II, technological advances in biotechnology led to the idea of developing single-cell proteins (SCP) using microorganisms, such as algae, bacteria and yeasts [78]. SCP possesses a high nutritional value, in which amino acid composition was similar to that of fish meal. Thus, SCP was usually used as animal feed and supplemental feedstuff material [79]. In the early 1970s, SCP production from methanol was studied intensively $[78,80]$. Based on these advantages, a series of large-scale
SCP production from methanol was established using high-cell-density fermentation strategy. A pilot plant equipped with an airlift fermentor $\left(20 \mathrm{~m}^{3}\right)$ was constructed by Mitsubishi Gas Chemical Company (MGC) for SCP production using methylotrophic bacteria in 1974 [81]. Imperial Chemical Industries (ICI) also constructed a $1500 \mathrm{~m}^{3}$ airlift reactor in the $1970 \mathrm{~s}$ and $1980 \mathrm{~s}$ [70]. When SCP is used as the source of animal feed protein, two factors are crucial: safety and nutritional value. Compared to methylotrophic bacteria, methylotrophic yeasts are safer without toxin formation. However, the protein content is lower than in bacteria. Moreover, the content of some amino acids is limited, such as methionine. Therefore, genetic and metabolic engineering should be adopted to obtain higher protein or amino acid contents in methanol-utilizing yeast.

Methylotrophs have also been used for production of various proteins, such as enzymes, antibodies and hormones. Green fluorescent protein (GFP) was usually used as a model protein to study the efficiency of vectors and promoters. Based on GFP production, the ability of two different expression vectors (pRK310 and pCM110) and promoters (Plac and PmxaF) for heterologous protein expression by $M$. extorquens was determined [82]. Results suggested that clones harboring PmxaF-GFPpCM110 produced approximately 100 -fold more GFP than those harboring Plac-GFP-pRK310 in shake flask experiments. The maximum growth rate and the biomass yield were $0.18 \mathrm{~h}^{-1}$ and $0.3 \mathrm{~g} / \mathrm{g}$ in fed-batch fermentation. Finally, $4 \mathrm{~g} / \mathrm{L}$ of GFP with yield of $80 \mathrm{mg} / \mathrm{g}$ was obtained using the recombinant harboring PmxaF-GFP-pCM110 [82], indicating $M$. extorquens might be a promising candidate for overexpression of recombinant proteins.

Enterocin P (EntP), a new pediocin-like bacteriocin, is produced by Enterococcus faecium strains. Based on a broad-spectrum antimicrobial property, EntP has a potential application as an effective food antimicrobial agent [83]. However, many enterococci contain potential virulence factors; thus, heterologous production of bacteriocins in safer hosts should be developed. Recently, $M$. extorquens was engineered for the production of EntP using methanol as the sole carbon and energy source [84]. $155 \mathrm{ng} / \mathrm{mL}$ of EntP was obtained in the recombinant, indicating an improvement of 25 -fold increase than E. coli on EntP production. Importantly, the purification of EntP was biologically active [84]. This study provides a new method for production of bacteriocins and proteins of interest from methanol by methylotrophs.

Cry1Aa is an insecticidal protein from Bacillus thuringiensis, which cannot colonize foliage and propagate vegetative. Thus, cry $1 A a$ gene from $B$. thuringiensis was heterologously expressed in a plant-colonizing methylotroph, M. extorquens [85]. Bipyramidal intracellular 
crystal-shaped inclusions were the same as the crystalline inclusions produced by $B$. thuringiensis. Comparisons of biomass and growth rate of wild-type and recombinant strains indicated that the production of recombinant protein does not influence the growth performance of the M. extorquens strain. However, just $4.5 \%$ of total protein was obtained, which is lower than that of other microorganisms (10-20\%), indicating more efforts are needed to increase the production of Cry1Aa in M. extorquens.

\section{Future perspectives}

Compared to genetically constructed methanol users, native methylotrophs show fast growth rates using methanol as sole carbon source, while only limited valuable metabolites can be produced due to the lack of efficient genetic tools for strain modification. Microbial consortia provide a new way to produce various chemicals from methanol. Two strategies were proposed for designing and constructing synthetic microbial consortia. One strategy is based on commensalism. In this case, elements and modules with different functions, such as protein scaffold elements or products synthesis modules, can be built in different strains, reducing the metabolic load on the single strain. The intermediate metabolites should be easily transported between the upstream and downstream strains under simultaneous co-culture condition (Fig. 3a). For example, methylotrophic bacteria were used to overproduce various amino acids from methanol, such as glutamate, lysine, threonine and serine, which can be further converted to other amino acids or derivatives, such as isoleucine, GABA and cadaverine, using engineered $E$. coli or other chassis microorganisms. The other strategy is based on cooperation. In this case, microbial consortia enable to rationally utilize different substrates and produce different products, in which one can consume methanol and the other can consume sugars under simultaneous co-culture condition (Fig. 3b). In addition, two kinds of products obtained from different microorganism can condense into a new product. For example, polyamide 56 (PA 56), a representative biopolymer, can be prepared by the polymerization of cadaverine with adipic acid [86]. Both monomers can be prepared using biological methods. As mentioned above, cadaverine can be produced from methanol by methylotrophic bacteria. Biosynthesis of adipic acid, an important platform chemical in industry, has also been realized in engineered E. coli [87]. Importantly, plenty of alkali was added to maintain the neutral conditions during microbial fermentation, increasing the osmotic pressure of the fermentation broth and inhibiting the performance of cell growth and metabolism [88]. Moreover, the cost of production and separation will increase. If

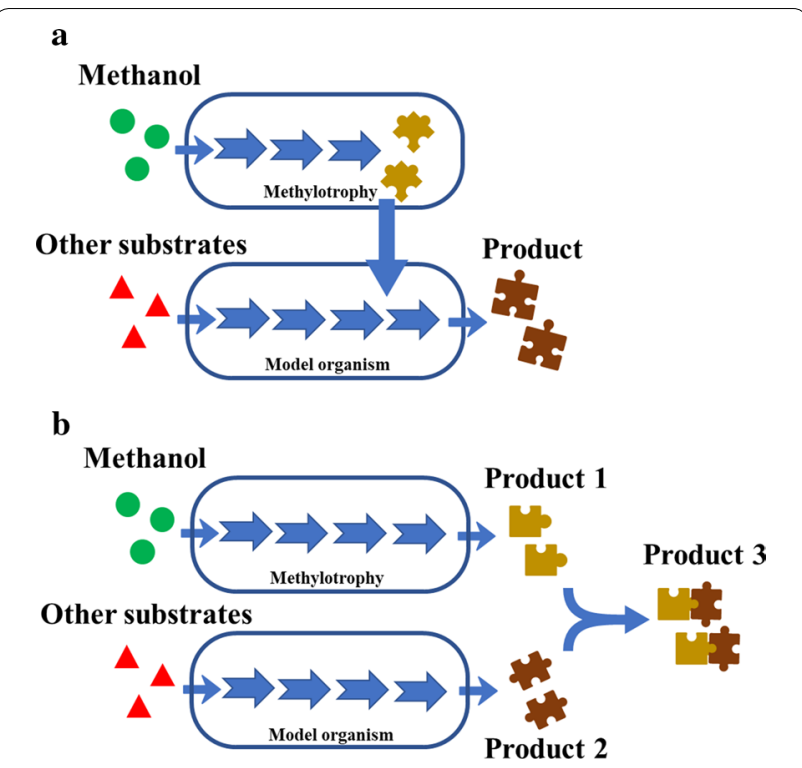

Fig. 3 Schematics of the metabolic interaction of the methylotrophy and model organism consortium. a Commensalism in synthetic microbial consortia. b Cooperation in synthetic microbial consortia

a co-culture system is built, adipic acid could be condensed with cadaverine, which will change environment and improve cell growth and metabolism.

Compared to native methylotrophs, the key limitation of synthetic methylotrophs is the low efficiency of methanol utilization. On one hand, methanol dehydrogenases (MDHs), catalyzing methanol to formaldehyde, have poor thermodynamic properties. Screening new enzyme genes or modifying current enzymes can overcome this limitation. On the other hand, the replenishment of Ru5P/Xu5P is crucial to sustain the RuMP/XuMP pathway running. Overexpressing key genes of pentose phosphate pathway or finding appropriate promoters which are sensitive to the concentration of formaldehyde may be useful for overcoming this limitation. Actually, methanol assimilation was indeed improved by expressing of heterologous the non-oxidative pentose phosphate pathway from $B$. methanolicus [62]. Moreover, the strategy of synthetic protein scaffold or scaffoldless self-assembly system to cluster key enzymes of methanol assimilation can also improve methanol conversion [59]. Based on high degree of reduction in methanol and metabolic flux in methanol dissimilation pathway, a new way for efficiency of methanol metabolism was raised. In this case, methanol was firstly oxidized to formate and subsequently to $\mathrm{CO}_{2}$, generating a large number of reducing equivalents, which will benefit the production of reducing fuels and chemicals [89]. Moreover, if $\mathrm{CO}_{2}$ fixation pathways are introduced into synthetic methylotrophs, such as 


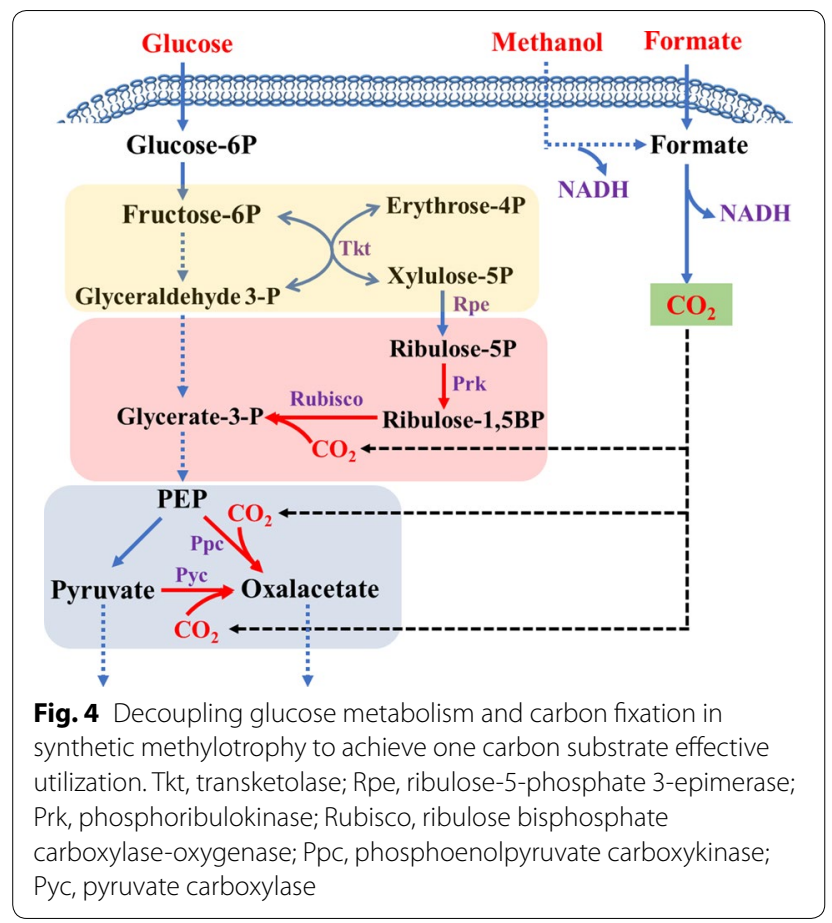

reductive TCA cycle or Calvin-Benson-Bassham pathway, the carbon loss problem will be solved (Fig. 4). However, we need also consider about energy conservation, redox balance and modules compatibility. Importantly, the other attractive one carbon compound, formate could also be used as co-carbon source.

\section{Conclusions}

Methanol is increasingly becoming an attractive substrate for the production of various chemicals owning to its low-cost and renewability. A methanol-based bioeconomy has been proposed, in which a variety of chemicals were produced from methanol via biological fermentation. As reviewed above, challenges still exist ahead of development of methanol-based bioeconomy. However, with the matureness of biological technologies, such as metabolic engineering, protein engineering and synthetic biology, methanol utilization and products yield will be improved. It might be seeing more commodity chemicals from methanol in the near future.

\section{Authors' contributions}

WMZ conceived, designed and drafted the paper. MS and QY wrote the part of 'PHAs and Amino acids'. ZXD and SJZ wrote the part of 'Organic acids and Fine chemicals.' FXX and WLD wrote the part of 'Other chemicals'. JFM and MJ wrote the part of 'Proteins'. All authors read and approved the final manuscript.

\section{Author details}

${ }^{1}$ State Key Laboratory of Materials-Oriented Chemical Engineering, College of Biotechnology and Pharmaceutical Engineering, Nanjing Tech University, No. 30 Puzhu Road, Pukou District Nanjing, Nanjing 211816, People's Republic of China. ${ }^{2}$ Jiangsu National Synergetic Innovation Center for Advanced
Materials (SICAM), Nanjing Tech University, Nanjing 211800, People's Republic of China.

\section{Acknowledgements}

Not applicable.

Competing interests

The authors declare that they have no competing interests.

Availability of data and materials

Not applicable.

\section{Consent for publication}

All authors consent the manuscript for publication in Biotechnology for Biofuels.

\section{Ethical approval and consent to participate}

Not applicable.

\section{Funding}

This work was supported by National Natural Science Foundation of China (Nos. 21706124, 21706125, 21727818, 31700092), the Key Science and Technology Project of Jiangsu Province (BE2016389), the Jiangsu Province Natural Science Foundation for Youths (BK20170993, BK20170997), the Jiangsu Synergetic Innovation Center for Advanced Bio-Manufacture of China (XTE1839), and Top-notch Academic Programs Project of Jiangsu Higher Education Institutions (PPZY2015B155, TAPP).

\section{Publisher's Note}

Springer Nature remains neutral with regard to jurisdictional claims in published maps and institutional affiliations.

Received: 10 July 2018 Accepted: 19 September 2018

Published online: 24 September 2018

\section{References}

1. Haynes CA, Gonzalez R. Rethinking biological activation of methane and conversion to liquid fuels. Nat Chem Biol. 2014;10:331-9.

2. Dai Z, Gu H, Zhang S, Xin F, Zhang W, Dong W, Ma J, Jia H, Jiang M. Metabolic construction strategies for direct methanol utilization in Saccharomyces cerevisiae. Bioresour Technol. 2017; 245.

3. Wi SG, Cho EJ, Lee DS, Lee SJ, Lee YJ, Bae HJ. Lignocellulose conversion for biofuel: a new pretreatment greatly improves downstream biocatalytic hydrolysis of various lignocellulosic materials. Biotechnol Biofuels. 2015;8:228

4. Lee OK, Hur DH, Nguyen DTN, Lee EY. Metabolic engineering of methanotrophs and its application to production of chemicals and biofuels from methane. Biofuel Bioprod Bior. 2016;10:848-63.

5. Olah GA. Beyond oil and gas: the methanol economy. Angew Chem Int Edit. 2005;44:2636-9.

6. Whitaker WB, Sandoval NR, Bennett RK, Fast AG, Papoutsakis ET. Synthetic methylotrophy: engineering the production of biofuels and chemicals based on the biology of aerobic methanol utilization. Curr Opin Biotech. 2015;33:165-75.

7. Schendel FJ, Bremmon C, Flickinger M, Guettler M, Hanson R. L-lysine production at 50 degrees $C$ by mutants of a newly isolated and characterized methylotrophic Bacillus sp. Appl Environ Microb. 1990;56:963-70.

8. Zhang WM, Zhang T, Wu SH, Wu MK, Xin FX, Dong WL, Ma JF, Zhang M, Jiang M. Guidance for engineering of synthetic methylotrophy based on methanol metabolism in methylotrophy. RSC Adv. 2017;7:4083-91.

9. Olah GA. Towards oil independence through renewable methanol chemistry. Angew Chem Int Edit. 2013;52:104-7.

10. Gao X, Chen JC, Wu Q, Chen GQ. Polyhydroxyalkanoates as a source of chemicals, polymers, and biofuels. Curr Opin Biotechnol. 2011;22:768-74.

11. Shah AA, Hasan F, Hameed A, Ahmed S. Biological degradation of plastics: a comprehensive review. Biotechnol Adv. 2008;26:246-65. 
12. Verlinden RAJ, Hill DJ, Kenward MA, Williams CD, Radecka I. Bacterial synthesis of biodegradable polyhydroxyalkanoates. J Appl Microbiol. 2007; 102:1437-49.

13. Orita I, Nishikawa K, Nakamura S, Fukui T. Biosynthesis of polyhydroxyalkanoate copolymers from methanol by Methylobacterium extorquens AM1 and the engineered strains under cobalt-deficient conditions. Appl Microbiol Biot. 2014;98:3715-25.

14. Wang Y, Yin J, Chen GQ. Polyhydroxyalkanoates, challenges and opportunities. Curr Opin Biotech. 2014:30:59-65.

15. Suzuki T, Yamane T, Shimizu S. Kinetics and effect of nitrogen-source feeding on production of poly-beta-hydroxybutyric acid by fed-batch culture. Appl Microbiol Biot. 1986;24:366-9.

16. Bourque D, Pomerleau Y, Groleau D. High-cell-density production of poly- $\beta$-hydroxybutyrate (PHB) from methanol by Methylobacterium extorquens: production of high-molecular-mass PHB. Appl Microbiol Biot. 1995:44:367-76.

17. Ezhov VA, Doronina NV, Shmareva MN, Trotsenko YA. Synthesis of highmolecular-mass polyhydroxybutyrate from methanol in Methyloligella halotolerans C2. Appl Biochem Micro. 2017;53:47-51.

18. Mokhtari-Hosseini ZB, Vasheghani-Farahani E, Heidarzadeh-Vazifekhoran A, Shojaosadati SA, Karimzadeh R, Darani KK. Statistical media optimization for growth and PHB production from methanol by a methylotrophic bacterium. Bioresour Technol. 2009;100:2436-43.

19. Höfer P, Choi YJ, Osborne MJ, Miguez CB, Vermette P, Groleau D. Production of functionalized polyhydroxyalkanoates by genetically modified Methylobacterium extorquens strains. Microb Cell Fact. 2010;9:70.

20. Cui L, Zhang C, Xing XH. Methylotrophic cell factory as a feasible route for production of high-value chemicals from methanol. Methane biocatalysis: paving the way to sustainability. Berlin: Springer; 2018. p. 199-211.

21. Yezza A, Fournier D, Halasz A, Hawari J. Production of polyhydroxyalkanoates from methanol by a new methylotrophic bacterium Methylobacterium sp GW2. Appl Microbiol Biot. 2006;73:211-8.

22. Ikeda M. Amino acid production processes. Adv Biochem Eng Biot. 2003;79:1-35

23. Brautaset $\mathrm{T}$, Jakobsen $\mathrm{OM}$, Josefsen $\mathrm{KD}$, Flickinger MC, Ellingsen TE. BacilIus methanolicus: a candidate for industrial production of amino acids from methanol at 50 degrees C. Appl Microbiol Biot. 2007;74:22-34.

24. Jakobsen ØM. Study and engineering of methanol assimilation and L-lysine production in the thermotolerant bacterium Bacillus methanolicus. 2008.

25. Motoyama H, Anazawa H, Katsumata R, Araki K, Teshiba S. Amino-acid production from methanol by Methylobacillus glycogenes mutants-isolation of L-glutamic acid hyper-producing mutants from M. glycogenes strains, and derivation of L-threonine and L-lysine-producing mutants from them. Biosci Biotech Bioch. 1993;57:82-7.

26. Motoyama H, Yano H, Terasaki Y, Anazawa H. Overproduction of L-lysine from methanol by Methylobacillus glycogenes derivatives carrying a plasmid with a mutated dapA gene. Appl Environ Microb. 2001;67:3064-70.

27. Brautaset T, Williams MD, Dillingham RD, Kaufmann C, Bennaars A, Crabbe E, Flickinger MC. Role of the Bacillus methanolicus citrate synthase II gene, citY, in regulating the secretion of glutamate in L-lysine-secreting mutants. Appl Environ Microb. 2003;69:3986-95.

28. Brautaset $T$, Jakobsen OM, Degnes KF, Netzer R, Naerdal I, Krog A, Dillingham R, Flickinger MC, Ellingsen TE. Bacillus methanolicus pyruvate carboxylase and homoserine dehydrogenase I and II and their roles for L-lysine production from methanol at 50A degrees C. Appl Microbiol Biot. 2010;87:951-64.

29. Hanson RS, Dillingham R, Olson P, Lee GH, Cue D, Schendel FJ, Bremmon C, Fliekinger MC. Production of L-lysine and some other amino acids by mutants of B. methanolicus. Berlin: Springer; 1996.

30. Gunji Y, Yasueda H. Enhancement of L-lysine production in methylotroph Methylophilus methylotrophus by introducing a mutant LysE exporter. J Biotechnol. 2006;127:1-13.

31. Sirirote P, Yamane T, Shimizu S. Production of L-serine from methanol and glycine by resting cells of a methylotroph under automatically controlled conditions. J Ferment Tech. 1986;64:389-96.

32. Hagishita T, Yoshida T, Izumi Y, Mitsunaga T. Efficient L-serine production from methanol and glycine by resting cells of Methylobacterium sp. strain MN43. Biosci Biotech Bioch. 1996;60:1604-7.
33. Aoki R, Wada M, Takesue N, Tanaka K, Yokota A. Enhanced glutamic acid production by a $\mathrm{H}^{+}$-ATPase-defective mutant of Corynebacterium glutamicum. Biosci Biotech Bioch. 2005;69:1466-72.

34. Arfman N, Dijkhuizen L, Kirchhof G, Ludwig W, Schleifer KH, Bulygina ES, Chumakov KM, Govorukhina NI, Trotsenko YA, White D, et al. Bacillusmethanolicus sp-nov, a new species of thermotolerant, methanol-utilizing, endospore-forming bacteria. Int J Syst Bacteriol. 1992;42:439-45.

35. Becker J, Wittmann C. Advanced biotechnology: metabolically engineered cells for the bio-based production of chemicals and fuels, materials, and health-care products. Angew Chem Int Edit. 2015;54:3328-50.

36. Wu MK, Zhang WM, Ji YL, Yi XY, Ma JF, Wu H, Jiang M. Coupled $\mathrm{CO}_{2}$ fixation from ethylene oxide off-gas with bio-based succinic acid production by engineered recombinant Escherichia coli. Biochem Eng J. 2017;117:1-6.

37. Zhang WM, Zhu JR, Zhu XG, Song M, Zhang T, Xin FX, Dong WL, Ma $J F$, Jiang M. Expression of global regulator IrrE for improved succinate production under high salt stress by Escherichia coli. Bioresource Technol. 2018;254:151-6.

38. Gao CJ, Yang XF, Wang HM, Rivero CP, Li C, Cui ZY, Qi QS, Lin CSK. Robust succinic acid production from crude glycerol using engineered Yarrowia lipolytica. Biotechnol Biofuels. 2016:9:179.

39. Cui Z, Gao C, Li J, Hou J, Lin CSK, Qi Q. Engineering of unconventional yeast Yarrowia lipolytica for efficient succinic acid production from glycerol at low pH. Metab Eng. 2017;42:126-33.

40. Knuf C, Nookaew I, Brown SH, McCulloch M, Berry A, Nielsen J. Investigation of malic acid production in Aspergillus oryzae under nitrogen starvation conditions. Appl Environ Microb. 2013;79:6050-8.

41. Ochsenreither K, Fischer C, Neumann A, Syldatk C. Process characterization and influence of alternative carbon sources and carbon-to-nitrogen ratio on organic acid production by Aspergillus oryzae DSM1863. Appl Microbiol Biot. 2014;98:5449-60.

42. Hu W, Liu J, Chen JH, Wang SY, Lu D, Wu QH, Li WJ. A mutation of Aspergillus niger for hyper-production of citric acid from corn meal hydrolysate in a bioreactor. J Zhejiang Univ-Sc B. 2014;15:1006-10.

43. Kuenz A, Gallenmuller Y, Willke T, Vorlop KD. Microbial production of itaconic acid: developing a stable platform for high product concentrations. Appl Microbiol Biot. 2012;96:1209-16.

44. Sonntag F, Buchhaupt M, Schrader J. Thioesterases for ethylmalonylCoA pathway derived dicarboxylic acid production in Methylobacterium extorquens AM1. Appl Microbiol Biot. 2014;98:4533-44.

45. Tobias J, Erb IAB, Volker B, Müller M, Fuchs G, Birgit EA. Synthesis of C5-dicarboxylic acids from C2-units involving crotonyl-CoA carboxylase/ reductase: The ethylmalonyl-CoA pathway. Proc Natl Acad Sci USA. 2007; 104:10631-6.

46. Erb TJ, Fuchs G, Alber BE. (2S)-Methylsuccinyl-CoA dehydrogenase closes the ethylmalonyl-CoA pathway for acetyl-CoA assimilation. Mol Microbiol. 2009;73:992

47. White NJ. Qinghaosu (Artemisinin): the price of success. Science. 2008;320:330-4.

48. Zhang FZ, Rodriguez S, Keasling JD. Metabolic engineering of microbial pathways for advanced biofuels production. Curr Opin Biotech. 2011;22:775-83.

49. Zhu WL, Cui JY, Cui LY, Liang WF, Yang S, Zhang C, Xing XH. Bioconversion of methanol to value-added mevalonate by engineered Methylobacterium extorquens AM1 containing an optimized mevalonate pathway. Appl Microbiol Biot. 2016;100:2171-82.

50. Kuzuyama T. Mevalonate and nonmevalonate pathways for the biosynthesis of isoprene units. Biosci Biotech Bioch. 2002;66:1619-27.

51. Harada H, Yu F, Okamoto S, Kuzuyama T, Utsumi R, Misawa N. Efficient synthesis of functional isoprenoids from acetoacetate through metabolic pathway-engineered Escherichia coli. Appl Microbiol Biot. 2009;81:915-25.

52. Vuilleumier S, Chistoserdova L, Lee MC, Bringel F, Lajus A, Zhou Y, Gourion B, Barbe V, Chang J, Cruveiller S, et al. Methylobacterium genome sequences: a reference blueprint to investigate microbial metabolism of 1 compounds from natural and industrial sources. PLOS ONE. 2009;4:e5584

53. Cui LY, Liang WF, Zhu WL, Sun MY, Zhang C, Xing XH. Medium redesign for stable cultivation and high production of mevalonate by recombinant Methtylobacterium extorquens AM1 with mevalonate synthetic pathway. Biochem Eng J. 2017;119:67-73. 
54. Liang WF, Cui LY, Cui JY, Yu KW, Yang S, Wang TM, Guan CG, Zhang C, Xing XH. Biosensor-assisted transcriptional regulator engineering for Methylobacterium extorquens AM1 to improve mevalonate synthesis by increasing the acetyl-CoA supply. Metab Eng. 2017;39:159-68.

55. Fernandes ES, Passos GF, Medeiros R, da Cunha FM, Ferreira J, Campos MM, Pianowski LF, Calixto JB. Anti-inflammatory effects of compounds alpha-humulene and (-)-trans-caryophyllene isolated from the essential oil of Cordia verbenacea. Eur J Pharmacol. 2007;569:228-36.

56. Sonntag F, Kroner C, Lubuta P, Peyraud R, Horst A, Buchhaupt M, Schrader $J$. Engineering Methylobacterium extorquens for de novo synthesis of the sesquiterpenoid alpha-humulene from methanol. Metab Eng. 2015;32:82-94

57. Dien SJV, Marx CJ, O'Brien BN, Lidstrom ME. Genetic characterization of the carotenoid biosynthetic pathway in Methylobacterium extorquens AM1 and isolation of a colorless mutant. Appl Environ Microb. 2003;69:7563

58. Muller JEN, Meyer F, Litsanov B, Kiefer P, Potthoff E, Heux S, Quax WJ, Wendisch VF, Brautaset T, Portais JC, et al. Engineering Escherichia coli for methanol conversion. Metab Eng. 2015;28:190-201.

59. Price JV, Chen L, Whitaker WB, Papoutsakis E, Chen W. Scaffoldless engineered enzyme assembly for enhanced methanol utilization. P Natl Acad Sci USA. 2016;113:12691-6.

60. Whitaker WB, Jones JA, Bennett RK, Gonzalez JE, Vernacchio VR, Collins SM, Palmer MA, Schmidt S, Antoniewicz MR, Koffas MA, et al. Engineering the biological conversion of methanol to specialty chemicals in Escherichia coli. Metab Eng. 2017;39:49-59.

61. Gonzalez JE, Bennett RK, Papoutsakis ET, Antoniewicz MR. Methanol assimilation in Escherichia coli is improved by co-utilization of threonine and deletion of leucine-responsive regulatory protein. Metab Eng. 2018:45:67-74.

62. Bennett RK, Gonzalez JE, Whitaker WB, Antoniewicz MR, Papoutsakis ET. Expression of heterologous non-oxidative pentose phosphate pathway from Bacillus methanolicus and phosphoglucose isomerase deletion improves methanol assimilation and metabolite production by a synthetic Escherichia coli methylotroph. Metab Eng. 2018;45:75-85.

63. Witthoff S, Schmitz K, Niedenfuhr S, Noh K, Noack S, Bott M, Marienhagen J. Metabolic engineering of Corynebacterium glutamicum for methanol metabolism. Appl Environ Microb. 2015;81:2215-25.

64. Lessmeier L, Pfeifenschneider J, Carnicer M, Heux S, Portais JC, Wendisch VF. Production of carbon-13-labeled cadaverine by engineered Corynebacterium glutamicum using carbon-13-labeled methanol as co-substrate. Appl Microbiol Biot. 2015;99:10163-76.

65. Liu YQ, Tu XH, Xu Q, Bai CX, Kong CX, Liu Q, Yu JH, Peng QQ, Zhou XS, Zhang $Y X$, et al. Engineered monoculture and co-culture of methylotrophic yeast for de novo production of monacolin $J$ and lovastatin from methanol. Metab Eng. 2018;45:189-99.

66. Jones JA, Vernacchio VR, Sinkoe AL, Collins SM, Ibrahim MHA, Lachance DM, Hahn J, Koffas MAG. Experimental and computational optimization of an Escherichia coli co-culture for the efficient production of flavonoids. Metab Eng. 2016;35:55-63.

67. Naerdal I, Pfeifenschneider J, Brautaset T, Wendisch VF. Methanol-based cadaverine production by genetically engineered Bacillus methanolicus strains. Microb Biotechnol. 2015:8:342-50.

68. Adkins J, Pugh S, McKenna R, Nielsen DR. Engineering microbial chemical factories to produce renewable "biomonomers". Front Microbiol. 2012;3:313.

69. Buschke N, Becker J, Schafer R, Kiefer P, Biedendieck R, Wittmann C. Systems metabolic engineering of xylose-utilizing Corynebacterium glutamicum for production of 1,5-diaminopentane. Biotechnol J. 2013;8:557-70.

70. Heider SAE, Wendisch VF. Engineering microbial cell factories: metabolic engineering of Corynebacterium glutamicum with a focus on non-natural products. Biotechnol J. 2015;10:1170-84.

71. Wittmann C, Becker J. The L-lysine story: from metabolic pathways to industrial production. Microbiol Monograph. 2007:39-70

72. Becker J, Zelder O, Häfner S, Schröder H, Wittmann C. From zero to heroDesign-based systems metabolic engineering of -lysine production. Metab Eng. 2011;13:159-68.
73. Mimitsuka T, Sawai H, Hatsu M, Yamada K. Metabolic engineering of Corynebacterium glutamicum for cadaverine fermentation. Biosci Biotech Bioch. 2007;71:2130-5.

74. Xu N, Wei L, Liu J. Biotechnological advances and perspectives of gamma-aminobutyric acid production. World J Microb Biot. 2017;33:64

75. Zhao WR, Huang J, Peng CL, Hu S, Ke PY, Mei LH, Yao SJ. Permeabilizing Escherichia coli for whole cell biocatalyst with enhanced biotransformation ability from L-glutamate to GABA. J Mol Catal B-Enzym. 2014;107:39-46.

76. Choi JW, Yim SS, Lee SH, Kang TJ, Park SJ, Jeong KJ. Enhanced production of gamma-aminobutyrate (GABA) in recombinant Corynebacterium glutamicum by expressing glutamate decarboxylase active in expanded pH range. Microb Cell Fact. 2015;14(1):21.

77. Irla M, Nærdal I, Brautaset T, Wendisch VF. Methanol-based $y$-aminobutyric acid (GABA) production by genetically engineered Bacillus methanolicus strains. Ind Crop Prod. 2016;106:12-20.

78. Litchfield JH. Single cell proteins. Science. 1983;219:740-6.

79. Ozyurt M, Deveci UD. Conversion of agricultural and industrial wastes for single cell protein production and pollution potential reduction: a review. Fresen Environ Bull. 2004;13:693-9.

80. Senior PJ, Windass J. The ici single cell protein process. Biotechnol Lett. 1980;2:205-10.

81. Urakami T, Terao I, Nagai I. Production of single cell protein by methanolusing bacteria. Hakkokogaku Kaishi. 1986;64:99-114.

82. Belanger L, Figueira MM, Bourque D, Morel L, Beland M, Laramee L, Groleau D, Miguez CB. Production of heterologous protein by Methylobacterium extorquens in high cell density fermentation. FEMS Microbiol Lett. 2004;231:197-204.

83. Cintas LM, Casaus P, Havarstein LS, Hernandez PE, Nes IF. Biochemical and genetic characterization of Enterocin $\mathrm{P}$, a novel sec-dependent bacteriocin from Enterococcus faecium P13 with a broad antimicrobial spectrum. Appl Environ Microb. 1997;63:4321-30.

84. Gutierrez J, Bourque D, Criado R, Choi YJ, Cintas LM, Hernandez PE, Miguez CB. Heterologous extracellular production of enterocin P from Enterococcus faecium P13 in the methylotrophic bacterium Methylobacterium extorquens. FEMS Microbiol Lett. 2005;248:125-31.

85. Choi YJ, Gringorten JL, Belanger L, Morel L, Bourque D, Masson L, Groleau D, Miguez CB. Production of an insecticidal crystal protein from Bacillus thuringiensis by the methylotroph Methylobacterium extorquens. Appl Environ Microb. 2008;74:5178-82.

86. Gao AQ, Zhang HJ, Sun G, Xie KL, Hou AQ. Light-induced antibacterial and UV-protective properties of polyamide 56 biomaterial modified with anthraquinone and benzophenone derivatives. Mater Design. 2017;130:215-22.

87. Yu JL, Xia XX, Zhong JJ, Qian ZG. Direct biosynthesis of adipic acid from a synthetic pathway in recombinant Escherichia coli. Biotechnol Bioeng. 2014;111:2580-6.

88. Guo SF, Yi XY, Zhang WM, Wu MK, Xin FX, Dong WL, Zhang M, Ma JF, $\mathrm{Wu} \mathrm{H}$, Jiang $\mathrm{M}$. Inducing hyperosmotic stress resistance in succinateproducing Escherichia coli by using the response regulator DR1558 from Deinococcus radiodurans. Process Biochem. 2017:61:30-7.

89. Von Borzyskowski LS, Carrillo M, Leupold S, Glatter T, Kiefer P, Weishaupt R, Heinemann M, Erb TJ. An engineered Calvin-Benson-Bassham cycle for carbon dioxide fixation in Methylobacterium extorquens AM1. Metab Eng. 2018:47:423-33.

90. Suzuki T, Yamane T, Shimizu S. Mass production of poly- $\beta$-hydroxybutyric acid by fully automatic fed-batch culture of methylotroph. Appl Microbiol Biot. 1986;23:322-9.

91. Cal AJ, Sikkema WD, Ponce MI, Franqui-Villanueva D, Riiff TJ, Orts WJ, Pieja AJ, Lee CC. Methanotrophic production of polyhydroxybutyrate-cohydroxyvalerate with high hydroxyvalerate content. Int J Biol Macromol. 2016;87:302-7. 